\title{
TEMPERATURA DE GERMINAÇÃO EM SEMENTES DE ESTILOSANTES ${ }^{1}$
}

\author{
ADRIANA PAULA D'AGOSTINI CONTREIRAS RODRIGUES², VALDEMIR ANTÔNIO LAURA³, \\ SILVIA RAHE PEREIRA ${ }^{4}$, ANDRÉIA DE LIMA SOUZA ${ }^{5}$, MIRIANNY ELENA DE FREITAS ${ }^{5}$
}

\begin{abstract}
RESUMO - Nos últimos anos, com o lançamento de novas cultivares de estilosantes, o uso destas tem se expandido e, consequentemente, a venda de sementes com as devidas exigências de boletins de análises. Dentre as condições consideradas ideais para a germinação destaca-se a temperatura. Objetivou-se neste trabalho, avaliar a germinação de sementes de Stylosanthes capitata e $S$. macrocephala submetidas às temperaturas constantes de $20,25,30$ e $35^{\circ} \mathrm{C}$, e às temperaturas alternadas de $20-30{ }^{\circ} \mathrm{C}, 20-35{ }^{\circ} \mathrm{C}$ e $25-35{ }^{\circ} \mathrm{C}$. Conclui-se que para o teste de germinação de sementes de Stylosanthes capitata e $S$. macrocephala, deve-se utilizar as temperaturas alternadas de $20-30{ }^{\circ} \mathrm{C}$ ou de $20-35{ }^{\circ} \mathrm{C}$ ou a temperatura constante de $25^{\circ} \mathrm{C}$.
\end{abstract}

Termos para indexação: Stylosanthes capitata, Stylosanthes macrocephala, leguminosa.

\section{GERMINATION TEMPERATURE IN STYLOSANTHES SEEDS}

\begin{abstract}
In recent years, with the launching of new stylosanthes cultivars, there has been a consequent increase in seed sales which are accompanied by the necessary analysis report. Among the conditions considered ideal for germination is the temperature. The objective of this study was to evaluate the germination of Stylosanthes capitata and Stylosanthes macrocephala seeds at constant temperatures of $20,25,30$ and $35^{\circ} \mathrm{C}$, and alternating temperatures of $20-30{ }^{\circ} \mathrm{C}, 20-35$ ${ }^{\circ} \mathrm{C}$ and $25-35^{\circ} \mathrm{C}$. It was concluded that for the germination test of Stylosanthes capitata and $S$. macrocephala, the alternating temperatures of $20-30{ }^{\circ} \mathrm{C}$ or $20-35^{\circ} \mathrm{C}$ or a constant temperature of $25^{\circ} \mathrm{C}$ should be used.
\end{abstract}

Index terms: Stylosanthes capitata, Stylosanthes macrocephala, legume.

${ }^{1}$ Submetido para publicação em 03/08/2009 Aceito em 30/06/2010.

${ }^{2}$ Eng. Agr., Prof. Dr. do Curso de Agronomia e do Mestrado em Produção e Gestão Agroindustrial, Universidade Anhanguera-UNIDERP, Rua Alexandre Herculano, 1400, Bairro Jardim Veraneio, CEP 79037-280, Campo Grande, MS, e-mail: adricontreiras@hotmail.com.

${ }^{3}$ Eng. Agr., Dr. Pesquisador da Embrapa Gado de Corte, CP 154, CEP 79002-970, Campo Grande, MS. e-mail: valdemir@cnpgc.embrapa.br.
${ }^{4}$ Bióloga, Doutoranda do Programa de Pós-Graduação em Ecologia e Recursos Naturais, Universidade Federal de São Carlos, CP 676, CEP 13565-905, São Carlos, SP. e-mail: silviarahe@gmail.com.

${ }^{5}$ Acadêmicas do Curso de Agronomia Universidade AnhangueraUNIDERP, CEP 79037-280, Campo Grande, MS, e-mail: alsguns49@ hotmail.com, miriannyelena@yahoo.com.br 


\section{INTRODUÇÃO}

O gênero Stylosanthes Sw., originário da América Central e do Sul, possui 45 espécies distribuídas no sudeste da Ásia, na África Tropical e nas Américas (Stace e Edye, 1984). É o gênero com maior número de cultivares dentre as leguminosas tropicais usadas como pastagens. No Brasil ocorrem 25 espécies (Lewis et al., 2005), sendo a maioria perene com potentes sistemas radiculares, tolerantes a seca e com grande capacidade de colonização por sua adaptação a solos de baixa fertilidade e simbiose com bactérias fixadoras de nitrogênio (Andrade e Karia, 2000). As principais espécies de Stylosanthes com potencial de uso no Brasil são $S$. guianensis, S. capitata e S. macrocephala (Karia e Andrade, 1996). O Stylosanthes capitata e o $S$. macrocephala são componentes da cultivar Estilosantes Campo Grande, lançada pela Embrapa.

Com o lançamento de novas cultivares de estilosantes nos últimos anos, o uso destas leguminosas tem se expandido e, conseqüentemente a sua comercialização para um mercado exigente em sementes com alta qualidade, que deve ser comprovada em boletins de análises. $\mathrm{O}$ teste de germinação é o principal parâmetro utilizado para a avaliação da qualidade fisiológica das sementes, possibilitando conhecer o potencial de germinação de um lote em condições ideais. Os resultados do teste são utilizados para determinar a taxa de semeadura, para a comparação de lotes e para a comercialização, pois possibilita a obtenção de resultados comparáveis entre laboratórios (Martins et al., 2008; Passos et al., 2008).

De acordo com as recomendações das Regras para Análise de Sementes (Brasil, 1992), a temperatura tem fundamental importância nos resultados do teste de germinação. Este fator age sobre a velocidade de absorção de água e reações bioquímicas que determinam todo o processo, afetando, conseqüentemente tanto a velocidade e uniformidade de germinação, como a germinação total (Bewley e Black, 1985; Carvalho e Nakagawa, 2000; Dousseau et al., 2008).

As sementes apresentam capacidade germinativa em limites bem definidos de temperatura, variável de espécie para espécie, o que caracteriza sua distribuição geográfica. A temperatura ótima é aquela em que a maior germinação é alcançada no menor tempo (Carvalho e Nakagawa, 2000; Ferreira e Borghetti, 2004). Segundo Nassif et al. (1998), para a maioria das espécies tropicais a temperatura ótima de germinação encontra-se entre 15 e $30^{\circ} \mathrm{C}$. Ainda segundo os autores, de maneira geral, temperaturas abaixo da ótima reduzem a velocidade de germinação, resultando em alteração da uniformidade de emergência, talvez em razão do aumento do tempo de exposição ao ataque de patógenos. Por outro lado, temperaturas acima da ótima aumentam a velocidade de germinação, embora somente as sementes mais vigorosas consigam germinar.

Há ainda espécies que respondem bem tanto às temperaturas constantes como às alternadas. A alternância de temperatura corresponde, provavelmente, a uma adaptação às flutuações naturais do ambiente (Popinigis, 1985). Portanto, conhecer os fatores ambientais que influenciam a germinação das sementes é de extrema importância.

As Regras para Análise de Sementes - RAS (Brasil, 1992) preconizam para as espécies Stylosanthes capitata e $S$. macrocephala o emprego de temperaturas alternadas $\left(20-35^{\circ} \mathrm{C}\right)$. Entretanto, as RAS foram publicadas há mais de 15 anos, antes, portanto, do lançamento da cultivar Campo Grande e da grande expansão do uso de estilosantes que tem demandado muitas análises laboratoriais e consequentemente maximizado o emprego de câmaras com alternância de temperaturas. Uma alternativa seria o emprego de temperaturas constantes, sendo esta uma vantagem nos testes de germinação em laboratórios, uma vez que para tanto se exige câmara de germinação menos sofisticada.

Assim, objetivou-se neste trabalho, avaliar a germinação de sementes de Stylosanthes capitata e S. macrocephala, quando submetidas às temperaturas constantes de $20^{\circ} \mathrm{C}, 25^{\circ} \mathrm{C}, 30^{\circ} \mathrm{C}$ e $35^{\circ} \mathrm{C}$, e às temperaturas alternadas de $20-30{ }^{\circ} \mathrm{C}, 20-35^{\circ} \mathrm{C}$ e $25-35^{\circ} \mathrm{C}$.

\section{MATERIAL E MÉTODOS}

O experimento foi conduzido no Laboratório Didático de Análise de Sementes da Universidade AnhangueraUNIDERP. Foram utilizadas sementes de estilosantes de cinco procedências (lotes), de cada uma das duas espécies componentes do Estilosantes Campo Grande, sendo elas: Stylosanthes capitata e $S$. macrocephala.

As sementes, previamente escarificadas mecanicamente, foram acondicionadas em caixas tipo gerbox (400 sementes/parcela), e semeadas sobre papel, umedecido com água destilada, com cinco repetições (procedências) para cada temperatura e, em seguida, colocadas para germinar em câmara climática tipo BOD. Foram realizados dois experimentos. No primeiro experimento, foram testadas quatro temperaturas 
constantes $\left(20^{\circ} \mathrm{C}, 25^{\circ} \mathrm{C}, 30^{\circ} \mathrm{C}\right.$ e $\left.35^{\circ} \mathrm{C}\right)$ para cada espécie e, no segundo, testaram-se as temperaturas alternadas de 20 $30{ }^{\circ} \mathrm{C}, 20-35^{\circ} \mathrm{C}$ e $25-35^{\circ} \mathrm{C}$, também para as duas espécies, comparadas com a melhor temperatura constante, resultante do primeiro experimento. Ambos os experimentos foram conduzidos sob fotoperíodo de oito horas. As contagens foram realizadas no quinto (primeira contagem), décimo (segunda contagem) e no décimo quinto dia (contagem final) do teste de germinação. Foi considerada como semente germinada aquela que apresentava raiz primária com pelo menos $2 \mathrm{~mm}$ de comprimento.

Utilizou-se o delineamento em blocos ao acaso, considerando cada procedência como um bloco, avaliandose separadamente cada espécie. Os dados tabulados e transformados em $\operatorname{arcsen}(\mathrm{x} / 100)^{1 / 2}$ foram submetidos à análise de variância, sendo que para o experimento 1 procedeu-se a regressão polinomial e para o experimento 2 as médias foram comparadas pelo teste de Tukey (5\%).

\section{RESULTADOS E DISCUSSÃO}

\section{Experimento 1}

Houve efeito significativo das temperaturas na porcentagem final de germinação de ambas as espécies (Figura 1). Para S. macrocephala a temperatura ótima foi $23,5{ }^{\circ} \mathrm{C}$ e para $S$. capitata, $25,1{ }^{\circ} \mathrm{C}$. No intervalo das temperaturas avaliadas não foram estabelecidas as temperaturas mínima e máxima de germinação dessas espécies. A média de germinação foi $45 \%$; semelhante aos resultados descritos por Alencar et al. (2009), para estas mesmas espécies de estilosantes, entre 30 e $55 \%$ para $S$. macrocephala e entre 25 e $55 \%$ para S. capitata.

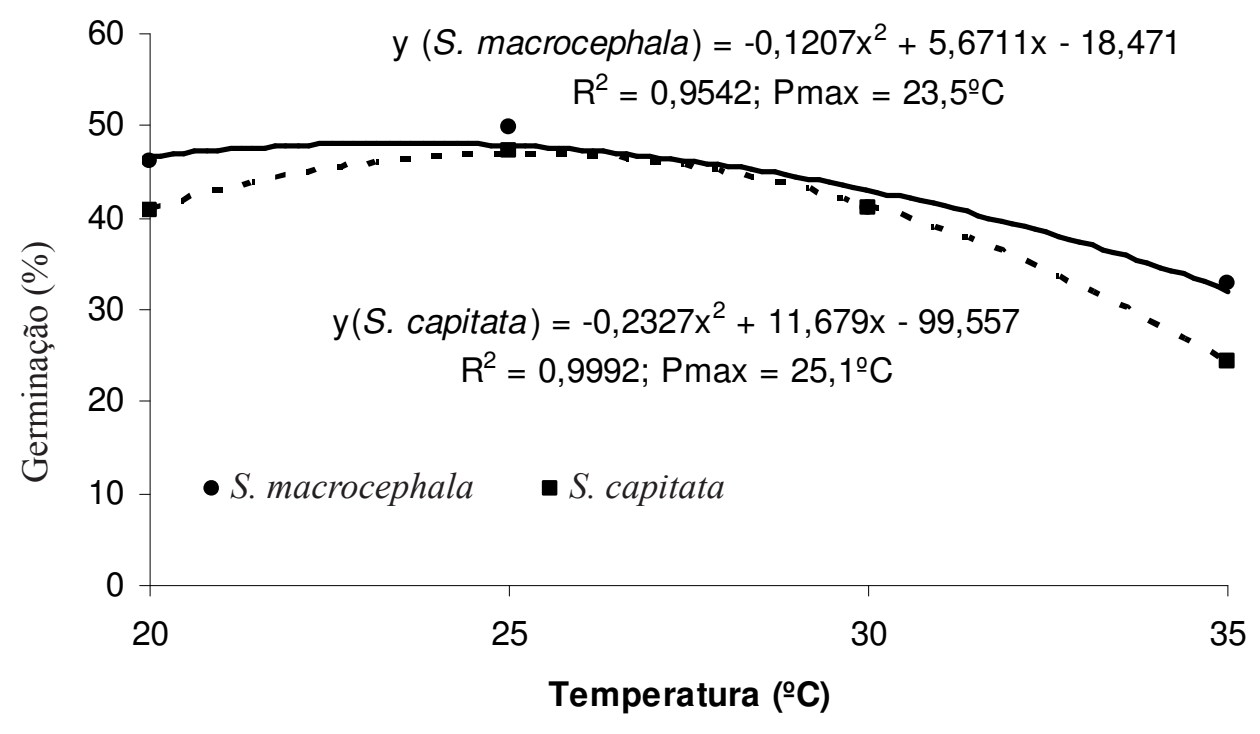

FIGURA 1. Porcentagem de germinação de sementes de estilosantes (Stylosanthes macrocephala e S. capitata) em diferentes temperaturas. Dados transformados em $\operatorname{arcsen}(\mathbf{x} / 100)^{1 / 2}$.

Esses resultados corroboram com os descritos por Alves et al. (2002), que observaram que a temperatura ótima de germinação para a maioria das espécies tropicais encontra-se entre $15^{\circ} \mathrm{C}$ e $30^{\circ} \mathrm{C}$. McIvor (1976) estudando a germinação de sementes escarificadas de sete espécies do gênero Stylosanthes (S. humilis, S. hamata, S. subsericea, S. fruticosa, S. viscosa, S. scabra e S. guyanensis) também encontrou resultados semelhantes aos do presente estudo. Este autor testou a germinação sob temperaturas constantes de $15,20,25,30,35,40{ }^{\circ} \mathrm{C}$, e obteve, para todas as espécies estudadas, uma maior porcentagem de germinação quando utilizou a temperatura de $25^{\circ} \mathrm{C}$, sendo que em temperaturas maiores e menores constatou uma redução nos valores da germinação. Silva (1984) avaliou a germinação de $S$. macrocephala, uma das espécies avaliadas por nosso estudo, e obteve os valores mais altos de germinação também a $25{ }^{\circ} \mathrm{C}$, independentemente da presença ou ausência de luz.

A porcentagem de sementes duras, para ambas as espécies, reduziu-se linearmente com o aumento da 
temperatura (Figura 2). Trabalhos desenvolvidos em diferentes espécies de Stylosanthes (Barriga, 1979; Battistin, 1981; Paterniani e Martins, 1979; Reis, 1984; Vieira, 1987) evidenciaram a existência de ampla variabilidade intra e interespecífica com relação à porcentagem de sementes duras e indicaram ainda, que tal variabilidade apresenta, provavelmente, um componente ambiental e outro genético, resultado da pressão de seleção em ambientes heterogêneos.

Para a variável porcentagem de sementes mortas, em ambas as espécies, houve efeito significativo das temperaturas (Figura 3). Para $S$. macrocephala a temperatura que proporciona a menor porcentagem de sementes mortas é $19,6^{\circ} \mathrm{C}$ e para $S$. capitata, $24,1^{\circ} \mathrm{C}$.

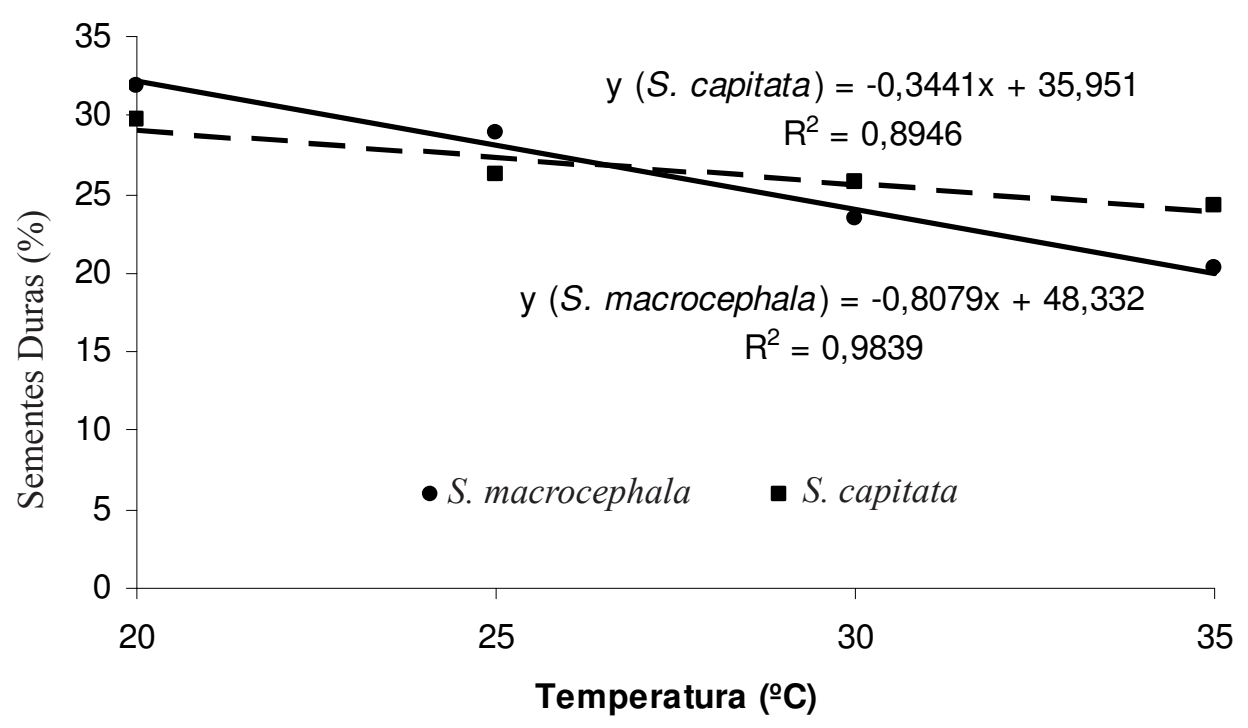

FIGURA 2. Porcentagem de sementes duras de estilosantes (Stylosanthes macrocephala e $S$. capitata), no teste de germinação, em diferentes temperaturas. Dados transformados em $\operatorname{arcsen}(\mathrm{x} / 100)^{1 / 2}$.



FIGURA 3. Porcentagem de sementes mortas de estilosantes (Stylosanthes macrocephala e $S$. capitata), no teste de germinação em diferentes temperaturas. Dados transformados em $\operatorname{arcsen}(\mathrm{x} / 100)^{1 / 2}$. 
Considerando os resultados obtidos nas três variáveis analisadas no experimento 1, para as duas espécies de estilosantes, foi estabelecido que para o experimento 2 , a temperatura constante de $25{ }^{\circ} \mathrm{C}$ seria comparada com as temperaturas alternadas.

\section{Experimento 2}

Houve efeito significativo dos tratamentos na porcentagem final de germinação. De acordo com a Figura 4 observa-se que apenas o tratamento $25-35{ }^{\circ} \mathrm{C}$ diferiu dos demais. Probert (2000) relata que para um grande número de espécies, a germinação das sementes não ocorre ou é severamente prejudicada em ambientes de temperatura constante. Em 85 espécies selecionadas dentro de 15 famílias diferentes, Steinbauer e Grigsby
(1957) observaram que mais de $80 \%$ apresentou maior percentual germinativo com temperaturas alternadas do que com as constantes. Por outro lado, McIvor (1976), avaliando a germinação de sete espécies de Stylosanthes descreve que tanto as temperaturas constantes como as alternadas produzem resultados similares na germinação das sementes, quando se utiliza baixas temperaturas. No entanto, temperaturas elevadas resultam em menor germinação quando as sementes são submetidas a temperaturas alternadas. Assim, a influência da alternância de temperatura na germinação de sementes parece variar entre diferentes espécies vegetais. Os resultados do presente estudo corroboram com os encontrados por McIvor (1976).

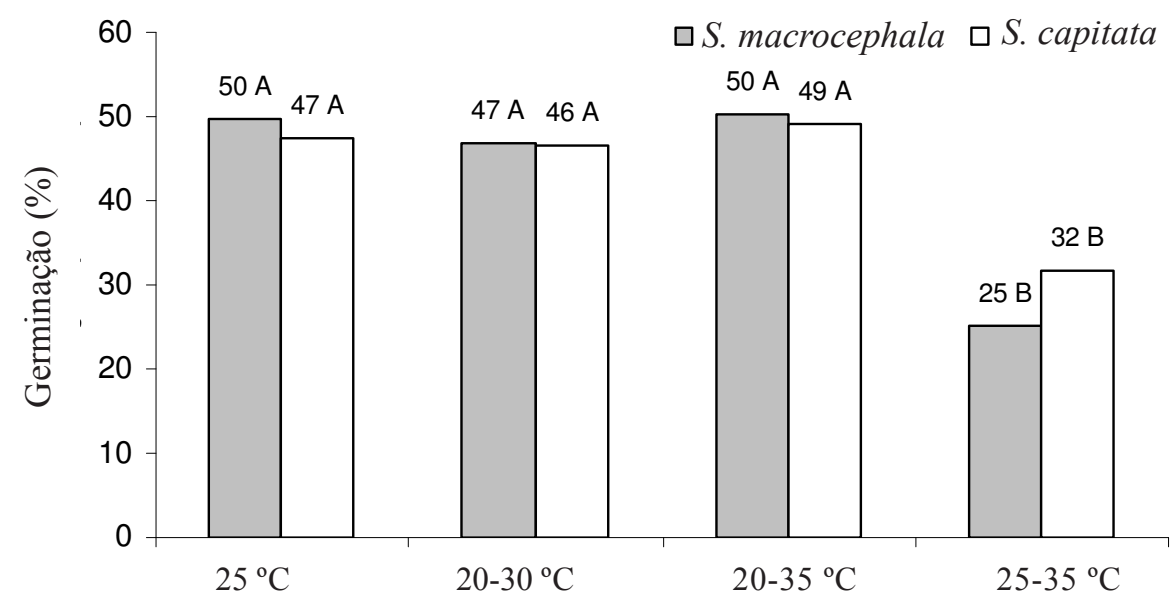

FIGURA 4. Porcentagem de germinação de sementes de estilosantes (Stylosanthes macrocephala e $S$. capitata) em diferentes temperaturas alternadas e constante. Dados transformados em $\operatorname{arcsen}(\mathrm{x} / \mathbf{1 0 0})^{1 / 2}$. As médias, para cada espécie, seguidas da mesma letra, não diferem entre si pelo teste de Tukey em $\mathbf{5 \%}$ de probabilidade.

$\mathrm{O}$ efeito mais pronunciado, na porcentagem de germinação, foi observado para o tratamento $25-35{ }^{\circ} \mathrm{C}$, onde ocorreu maior redução da mesma. De acordo com Popinigis (1985) e Marcos Filho (1986) o efeito de temperaturas altas, restritivas à germinação, é explicado por possíveis alterações enzimáticas, pela condição fisiológica da semente ou pela insolubilidade do oxigênio nessas condições, aumentando suas exigências e acelerando a velocidade respiratória das sementes.

Observando-se a Figura 5, conclui-se que não houve efeito dos tratamentos na porcentagem de sementes duras de S. capitata. Entretanto, para S. macrocephala houve efeito significativo. $\mathrm{O}$ tratamento $25-35{ }^{\circ} \mathrm{C}$ apresentou a menor porcentagem de sementes duras quando comparado com o tratamento $25{ }^{\circ} \mathrm{C}$. Os tratamentos $20-30{ }^{\circ} \mathrm{C}$ e 20-35 ${ }^{\circ} \mathrm{C}$ não diferiram entre si e nem tampouco dos demais tratamentos. Segundo Fernandes et al. (2000), a proporção de sementes duras produzidas por Stylosanthes varia de acordo com a espécie ou variedade, o ano e o local de produção. Condições de altas temperaturas e pouca disponibilidade de água favorecem a produção de sementes duras, podendo tal proporção alcançar níveis de $60 \%$ a $90 \%$.

A porcentagem de sementes mortas foi influenciada 
pelos tratamentos (Figura 6). Para ambas as espécies, a maior porcentagem de sementes mortas foi obtida no tratamento $25-35^{\circ} \mathrm{C}$, não havendo diferença entre os demais tratamentos.

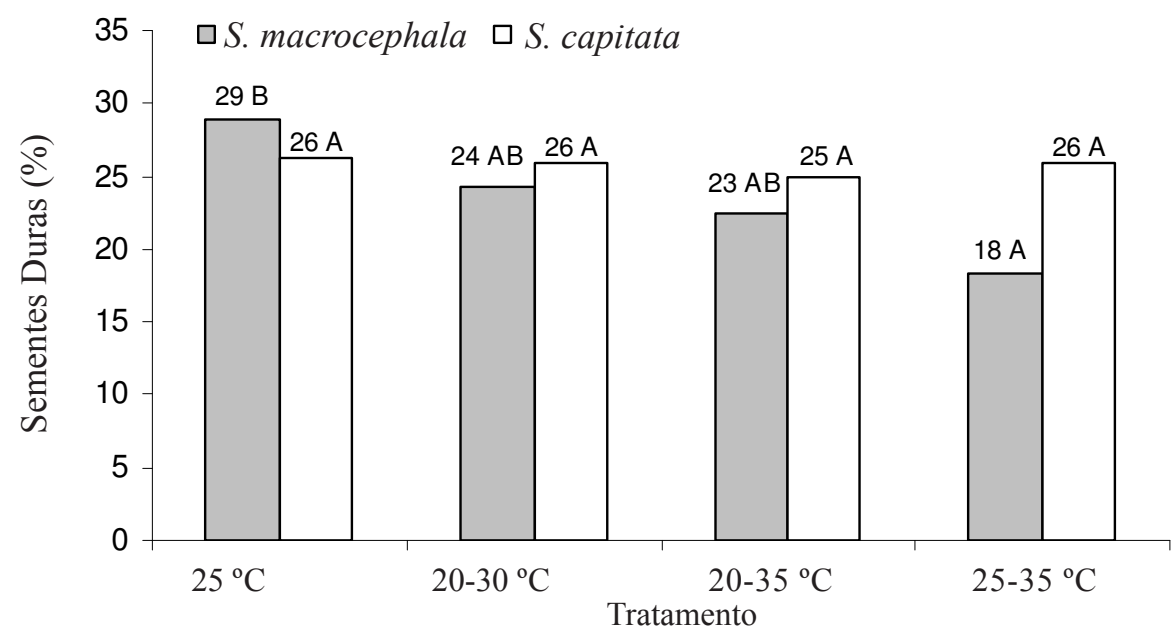

FIGURA 5. Porcentagem de sementes duras de estilosantes (Stylosanthes macrocephala e $S$. capitata), no teste de germinação em diferentes temperaturas alternadas e constante. Dados transformados em $\operatorname{arcsen}(\mathrm{x} / 100)^{1 / 2}$. As médias, para cada espécie, seguidas da mesma letra, não diferem entre si pelo teste de Tukey em $5 \%$ de probabilidade.

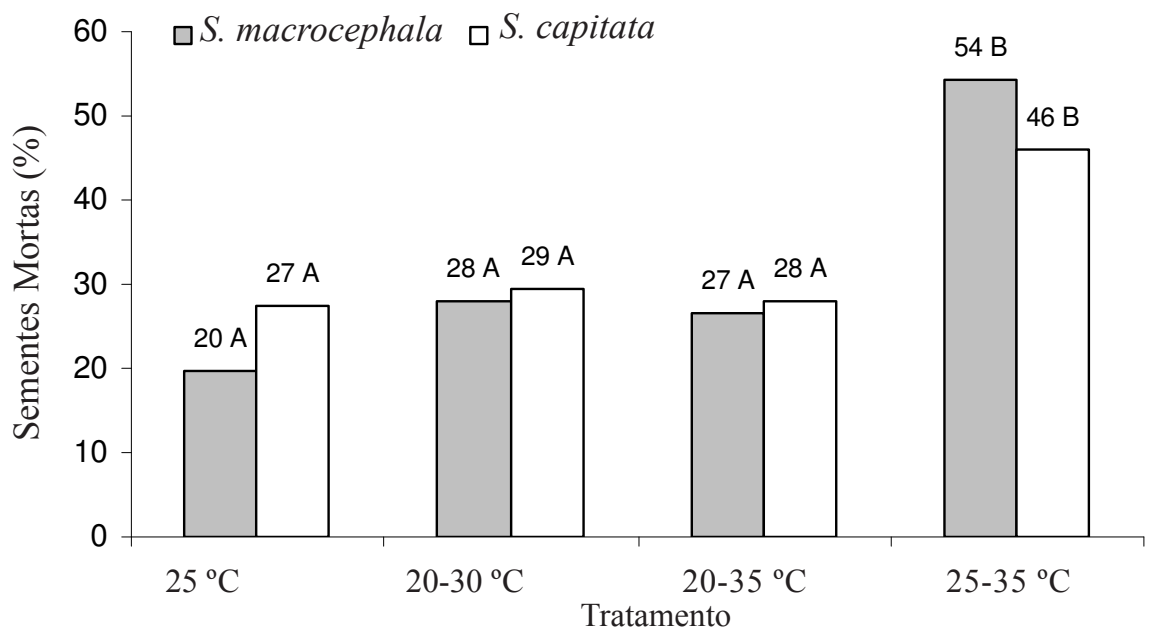

FIGURA 6. Porcentagem de sementes mortas de estilosantes (Stylosanthes macrocephala e $S$. capitata), no teste de germinação em diferentes temperaturas alternadas e constante. Dados transformados em $\operatorname{arcsen}(\mathrm{x} / 100)^{1 / 2}$. As médias, para cada espécie, seguidas da mesma letra, não diferem entre si pelo teste de Tukey em $5 \%$ de probabilidade.

A alternância da temperatura pode proporcionar melhores condições de germinação para sementes de algumas espécies tropicais, como constataram Gomes e Bruno (1992) para Bixa orellana (L.) e Castellani e Aguiar (1998) para Trema micrantha (L.) Blume. As sementes que respondem à alternância da temperatura apresentam mecanismos enzimáticos que funcionam em diferentes temperaturas (Vázquez-Yanes e Orozco-Segovia, 1987) e, segundo Popinigis (1985) e Borges e Rena (1993), essa resposta corresponde, provavelmente, a uma adaptação às 
flutuações naturais do ambiente.

As Regras para Análise de Sementes (Brasil, 1992) preconizam para as espécies de estilosantes o emprego de temperaturas alternadas $\left(20-35^{\circ} \mathrm{C}\right)$. Este tratamento não diferiu estatisticamente da temperatura alternada 20 $30{ }^{\circ} \mathrm{C}$ e da temperatura constante $25^{\circ} \mathrm{C}$. O emprego de temperaturas constantes pode ser uma vantagem nos testes de germinação em laboratórios, uma vez que para tanto se exige câmara de germinação menos sofisticada, sendo que para as espécies Stylosanthes capitata e S. macrocephala pode-se empregar a temperatura constante de $25^{\circ} \mathrm{C}$.

\section{CONCLUSÕES}

Para o teste de germinação de sementes de Stylosanthes capitata e $S$. macrocephala, recomenda-se o emprego das temperaturas alternadas $20-30{ }^{\circ} \mathrm{C}$ ou $20-35{ }^{\circ} \mathrm{C}$ ou a temperatura constante de $25^{\circ} \mathrm{C}$.

\section{REFERÊNCIAS}

ALENCAR, K.M. de C.; LAURA, V.A.; CONTREIRAS RODRIGUES, A.P.D.; RESENDE, R.M.S. Tratamento térmico para superação da dormência em sementes de Stylosanthes SW. (Fabaceae Papilionoideae). Revista Brasileira de Sementes, v.31, n.2, p.164-170, 2009.

ALVES, E.U.; PAULA, R.C.; OLIVEIRA, A.P.; BRUNO, R.L.A.; DINIZ, A.A. Germinação de sementes e Mimosa caesalpiniaefolia Benth. em diferentes substratos e temperaturas. Revista Brasileira de Sementes, v.24, n.1, p.169-178, 2002.

ANDRADE, R.P.; KARIA, C.T. O uso de Stylosanthes em pastagens no Brasil. In: SIMPÓSIO DE FORRAGICULTURA E PASTAGEM, 1., 2000, Lavras. Anais... Lavras: Universidade Federal de Lavras, 2000, p.273-309.

BARRIGA, J.P. Autoecologia de Stylosanthes humilis H.B.K.: Avaliação da variabilidade morfológica e estudos da biologia da semente. 1979. 97f. Dissertação (Mestrado)

- Escola Superior de Agricultura Luiz de Queiroz, Universidade de São Paulo.

BATTISTIN, A. Estudo biossistemático de diferentes taxons do gênero Stylosanthes Sw. (LeguminosaePapilionoideae). 1981. 106f. Dissertação (Mestrado) - Escola Superior de Agricultura Luiz de Queiroz, Universidade de São Paulo.

BEWLEY, J.D.; BLACK, M. Viability, dormancy and environmental control. In: BEWLEY, J.D.; BLACK, M. (Ed.). Physiology and biochemistry of seeds. New York: Springer - Verlag, 1985. v.2. 328p.

BORGES, E.E.L.; RENA, A.B. Germinação de sementes. In: AGUIAR, I.B.; PIÑA-RODRIGUES, F.C.M.; FIGLIOLIA, M.B. (Coord.). Sementes florestais tropicais. Brasília: Abrates, 1993, p.83-135.

BRASIL. Ministério da Agricultura e Reforma Agrária. Secretaria Nacional de Defesa Agropecuária. Departamento Nacional de Defesa Vegetal. Coordenação de Laboratório Vegetal. Regras para análise de sementes. Brasília, DF, 1992. 365p.

CARVALHO, N.M.; NAKAGAWA, J. Sementes: ciência, tecnologia e produção. Jaboticabal: FUNEP, 2000, 588p.

CASTELLANI, E.D.; AGUIAR, I.B. Condições preliminares para a germinação de sementes de candiúba (Trema micrantha (L.) Blume). Revista Brasileira de Engenharia Agrícola e Ambiental, v.2, n.1, p.80-83, 1998.

DOUSSEAU, S.; ALVARENGA, A.A.; ARANTES, L.O.; OLIVEIRA, D.M.; NERY, F.C. Germinação de sementes de tanchagem (Plantago tomentosa Lam.): influência da temperatura, luz e substrato. Ciência e Agrotecnologia, v.32, n.2, p.438-443, 2008.

FERNANDES, C.D.; GROF, B.; CARVALHO, J. Escarificação mecânica de sementes de Stylosanthes spp. com beneficiadora de arroz. Campo Grande: Embrapa Gado de Corte, 2000. 4p. (Embrapa Gado de Corte. ComunicadoTécnico, 60).

FERREIRA, A.G.; BORGHETTI, F. Germinação: do básico ao aplicado. Porto Alegre: Artmed. 2004. 323p.

GOMES, S.M.S.; BRUNO, R.L. Influência da temperatura e substratos na germinação de sementes de urucum (Bixa orellana L.). Revista Brasileira de Sementes, v.14, n.1, p.47-50, 1992 .

KARIA, C.T.; ANDRADE, R.P. de. Caracterização e avaliação preliminar de espécies forrageiras no Centro de Pesquisa Agropecuária dos Cerrados. In: SIMPÓSIO SOBRE OS CERRADOS, 8., Brasília. 1996. Anais... Planaltina: Embrapa-CPAC, 1996, p.471-475.

LEWIS, G.L.; MACKINDER B.; LOCK, M. Legumes of the World. Royal Botanic Gardens, Kew, 2005, 578p.

MARCOS FILHO, J.; CICERO, S.M.; SILVA, W.R. (Ed.). Atualização em produção de sementes. Campinas, Fundação Cargill, 1986. 223p. 
MARTINS, C.C.; MACHADO, C.G.; NAKAGAWA, J. Temperatura e substrato para o teste de germinação de sementes de barbatimão (Stryphnodendron adstringens (Mart.) Coville (Leguminosae). Revista Árvore, v.32, n.4, p.633-639, 2008.

McIVOR F.G. Germination characteristics of seven Stylosanthes species. Australian Journal Experimental Agriculture and Animal Husbandry, v.16, p.723-728, 1976.

NASSIF, S.M.L.; VIEIRA, I.G.; FERNADES, G.D. Fatores externos (ambientais) que influenciam na germinação de sementes. Piracicaba: IPEF/LCF/ESALQ/ USP, Informativo Sementes IPEF,1998. Disponivel em: < http://www.ipef.br/tecsementes/germinacao.asp $>$. Acesso em: 19 abr. 2010.

PASSOS, M.A.A.; SILVA, F.J.B.C.; SILVA, E.C.A.; PESSOA, M.M.L.; SANTOS, R.C. Luz, substrato e temperatura na germinação de sementes de cedro-vermelho. Pesquisa Agropecuária Brasileira, v.43, n.2, p.281-284. 2008.

PATERNIANI, M.L.S.; MARTINS, P.S. Variabilidade genética da dormência de sementes em populações de Stylosanthes guianensis (Aubl.) Sw. (leguminosaePapilionoideae). Piracicaba: Instituto de Genética/ESALQ, 1979. (Relatório Científico).

POPINIGIS, F. Fisiologia da semente. Brasília: AGIPLAN, 1985. 289p.
PROBERT, R.J. The role of temperature in the regulation of seed dormancy and germination. In: FENNER, M. (Ed.). Seeds: The ecology of regeneration in plant communities. Wallingford: CABI Publishing, 2000. 261-292p.

REIS, M.S. Autoecologia de diferentes espécies de Stylosanthes Sw.: análise da alocação de energia e estudos da biologia da semente. 1984. 170f. Tese (Doutorado em Agronomia) - Escola Superior de Agricultura Luiz de Queiroz, Universidade de São Paulo. Piracicaba.

SILVA, J.C.S. GerminaçãodeStylosanthes macrocephala. 1984. 90f. Dissertação (Mestrado) - Universidade Estadual de Campinas, São Paulo.

STACE, H.M.; EDYE, L.A. The biology and agronomy of Stylosanthes. Sidney: Academic Press, 1984. 636p.

STEINBAUER, G.P.; GRIGSBY, B. Interactions of temperature, light and moistening agent in the germination of leed seeds. Weeds, v.5, p.681-688, 1957.

VÁZQUEZ-YANES， C.; OROZCO-SEGOVIA, A. Fisiología ecológica de semillas en la Estación de Biologia Tropical "Los Tuxtlas", Veracruz, México. Revista de Biologia Tropical, v.35, n.1, p.85-96, 1987.

VIEIRA, I.C.G. Distribuição fracionária de energia e biologia da semente de Stylosanthes Angustifolia Vog. (Leguminosae Papilonoideae). 1987. 128f. (Dissertação de Mestrado) Escola Superior de Agricultura Luiz de Queiroz, Universidade de São Paulo. 